\title{
DETERMINATION OF VERTICAL INDICATORS OF GROUND DEFORMATION IN THE OLD AND MAIN CITY OF GDANSK AREA BY APPLYING UNCONVENTIONAL METHOD OF ROBUST ESTIMATION
}

\author{
Marek Hubert ZIENKIEWICZ* and Radosław BARYŁA
}

University of Warmia and Mazury in Olsztyn, Oczapowskiego 1, 10-719 Olsztyn, Poland

*Corresponding author's e-mail: marek.zienkiewicz@uwm.edu.pl

\begin{tabular}{l} 
ARTICLE INFO \\
\hline Article history: \\
Received 16 March 2015 \\
Accepted 1 June 2015 \\
Available online 9 June 2015
\end{tabular}

Keywords:

$\mathrm{M}_{\text {split }}$ estimation

Robust estimation

Deformation analysis

Virtual functional model

Split functional model

\section{ABSTRACT}

It is well known that the reference points' stability is a very important issue in the geodetic methods of determining the displacements. The methodology of the geodetic deformation analysis requires to conduct the research of determining a stable reference datum, before the deformation indicators will be determined. However, the methods of determining the reliable values of the monitored point displacements, despite the instability of the reference points, can be considered as a supplement to the classical deformation analysis strategies. In this paper, we present application of method of the estimation of parameters in a split functional model to determine the vertical indicators of leveling network deformation, in which reference datum was unstable. The computations were realized on the geodetic control network designed in the area of the Old and Main City of Gdansk.

\section{INTRODUCTION}

Development of new technologies and strategies in civil engineering structures monitoring is one of the most important problems in modern geodesy. Deformation analysis process consists of two main stages: acquisition of geodetic observations (field measurements) and development and analysis of data. The choice of the appropriate method to determine displacements depends on, among others, the type designated deformation indicators, the accuracy aspects of designated shifts, geodetic control network size and the control measurements frequency. Development of new technologies has a significant impact on increasing the deformation monitoring efficiency of the tested object. Currently, in order to improve the quality of the results, among others, the satellite positioning technologies is applied. The application of the Global Navigation Satellite System (GNSS) to determine ground deformation indicators were subjected to detailed empirical analysis in a several scientific publications (e.g. Baryła and Paziewski, 2012; Langbein, 2003; Palano et al., 2008).

The application of GNSS measurements may influence on high accuracy of the obtained coordinates. However, the vertical coordinate, among the components obtained by using GNSS positioning, is characterized by the lowest accuracy. This is due to, among others, the impact of the systematic errors of the ionosphere and the troposphere on estimated coordinate values. Therefore, determination of vertical displacements of the monitored points using satellite measurement techniques require conducting researches on the influence of the ionosphere (e.g. Kashani et al., 2007) and the troposphere (e.g., Wielgosz et al., 2011) for the GNSS signals propagations. Thus, in certain cases, the optimal GNSS leveling strategies can significantly improve the accuracy of the determining height component (Stępniak et. al., 2013). On the other hand, in the case of determining heights coordinates, it is recommended to supplement GNSS measurements by observations obtained by classical precise leveling (e.g. Erol et al., 2004). The risk of unfavorable location of the monitored points to perform the satellite measurements is another serious limitation of GNSS methods in monitoring ground movements (see, e.g. Wielgosz et al. 2011). Therefore, the geometric leveling will still be applied in the deformation analysis, either as a supplement and base measurement.

The use of traditional measurement technology to determine displacement of the monitored points is often associated with risk of receiving the outliers in observation sets. For that reason, the development of the observations obtained by traditional measurement methods requires to choose the appropriate method of geodetic observations adjustment. The methods of geodetic observations adjustments due to their properties can be divided into three main groups: neutral, robust and weak estimation methods 
(Wiśniewski, 2005). Currently, since the pioneering publication (Huber, 1981), in practice the methods of robust estimation are commonly used (e.g. Stroner et al., 2014; Labant et al., 2011; Wiśniewski 2014b; Xu, 1989; Yang, 1994). In these methods, the influence of the outliers on the final estimation results are eliminated or at least reduced at iterative process. Another approach to eliminate the outliers in an observation sets is detection of the outliers based on a statistical tests (e.g. Baarda, 1968; Prószyński, 2010; Hekimoglu et. al., 2011). In practice, application of computational strategy relating to the principles of robust $\mathrm{M}$ - estimation must be preceded by studies on the application of appropriate weight function (e.g. weight function of Huber, Hampel, Tukey or Danish), which preferably eliminate the influence of the outliers on the final adjustment results of a particular geodetic network (e.g. Banaś and Ligas, 2014; Nowel, 2015a). This issue can be solved by determining MSR factor (mean success rate) based on an empirical analysis of the simulated geodetic network (e.g. Hekimoglu and Koch, 1999, 2000). On the other hand, the engineering problems appear where the outliers (not related with gross errors in observations), can constitute of the final form of the designated estimators (e.g. Cellmer, 2014).

Application of the robust $\mathrm{M}$ - estimation does not necessarily refer to the gross error in the measurement results. The robust $M$ - estimation algorithms can be used to reduce influence of unstable reference points on designated displacements vector of monitored points, e.g. robust S - transformation of adjusted coordinates differences (e.g. Caspary, 1988) and robust M - estimation of displacements of unadjusted observations differences (Nowel and Kamiński, 2014; Nowel, 2015b). On the other hand, from a practical point of view, a very interesting issue is to apply concept of hybrid M-estimation to simultaneous "muting" of the unstable reference points and an observations contaminated by gross errors (Czaplewski and Wiśniewski, 2008).

The subject of the outliers generated by unstable reference points is a problem, which often arise in a practice, especially in the case of classical measurements. In paper (Baryła and Paziewski, 2012), the authors note that using traditional measurement methods in the deformation and displacements study, requires to use reference points located in the vicinity of the test object. Thus, it may happen that the reference point is located on unstable ground. Of course, the issue of reference points stability concerns also GNSS measurements. For that reason, deformation analysis methodology involves also the study of the reference points stability. For this purpose it can be applied, among others, methods based on a rank tests (e.g. Duchnowski, 2010, 2011) or robust free adjustment (Zienkiewicz, 2013). Instability of the reference points occurred, among other, on the area of the Old and Main City of Gdansk (Baryła et al., 2009; Baryła and Paziewski, 2012). Of course, reference points stability testing is very important, however it can extend the deformation analysis process. However, in practice the situation may occur, when time constraints and a high security priority require to carry out the deformation study of the object, using the reference point of uncertain stability. Note that the control measurement results are a set of being a realization of one random variable $Y \sim P_{X} \quad$ with following functional model $\mathbf{v}=\mathbf{y}-\mathbf{A X}$ (where $\mathbf{A} \in \mathfrak{R}^{n, r}$ - known coefficient matrix, $\mathbf{X} \in \mathfrak{R}^{r}$ - unknown vector of the parameters, $\mathbf{v} \in \mathfrak{R}^{n}$ - vector of residuals, and $\mathbf{y} \in \mathfrak{R}^{n}$ observation vector). Therefore, from a theoretical point of view, occurrence the outliers (generated by unstable reference points as well as measurement gross errors in observations) in observation sets $\mathbf{y}$ is related with occurrence in observations set of an observation which is a realization of a random variable with a different probability distribution than $Y \sim P_{\mathbf{X}}$. In addition, it should be noted, that the measurements results carried out in two different measurement epochs are realizations of two random variables with different probability distributions, respectively $Y_{\alpha} \sim P_{X_{\alpha}}$ for the first and $Y_{\beta} \sim P_{X_{\beta}}$ for the second measurement epoch. Therefore, determination of monitored points coordinates not burdened by the influence of unstable reference points, may occur by using the concept of estimation parameters in a split functional model of geodetic observations (e.g. Wiśniewski, 2010; Zienkiewicz, 2015).

Theoretical foundation of $\mathrm{M}_{\text {split }}$ estimation is the assumption, that each of observation $y_{i}$ can be a realization of one of the two competitive random variables (e.g. Wiśniewski, 2009). The consequence of this assumption is a split of conventional functional model $\mathbf{v}=\mathbf{y}-\mathbf{A X}$ into two competitive functional models $\quad \mathbf{v}_{\alpha}=\mathbf{y}-\mathbf{A} \mathbf{X}_{\alpha} \quad$ and $\quad \mathbf{v}_{\beta}=\mathbf{y}-\mathbf{A} \mathbf{X}_{\beta}$ (Wiśniewski, 2009a, 2009b), where $\mathbf{X}_{\alpha}$ and $\mathbf{X}_{\beta}$ are competitive versions of parameter $\mathbf{X}$, whereas $\mathbf{v}_{\alpha}$ and $\mathbf{v}_{\beta}$ are two versions of a vector of random measurement errors, concerning the same observation vector $\mathbf{y}$. The competitive models in deformation analysis of geodetic network, can be a functional models into two measurement epochs. Due to the fact, that the outliers occur in observations set $\mathbf{y}$, which are generated by unstable reference points, they are also a realization of a certain random variable (in this paper labeled as $Y_{\zeta} \sim P_{X_{\zeta}}$ ), so for this variable can be assign an additional (virtual) functional model $\mathbf{v}_{\text {virtual }}=\mathbf{y}-\mathbf{A} \mathbf{X}_{\text {virtual }}$ which absorbs the outliers (Wiśniewski, 2010; Zienkiewicz, 2015). 


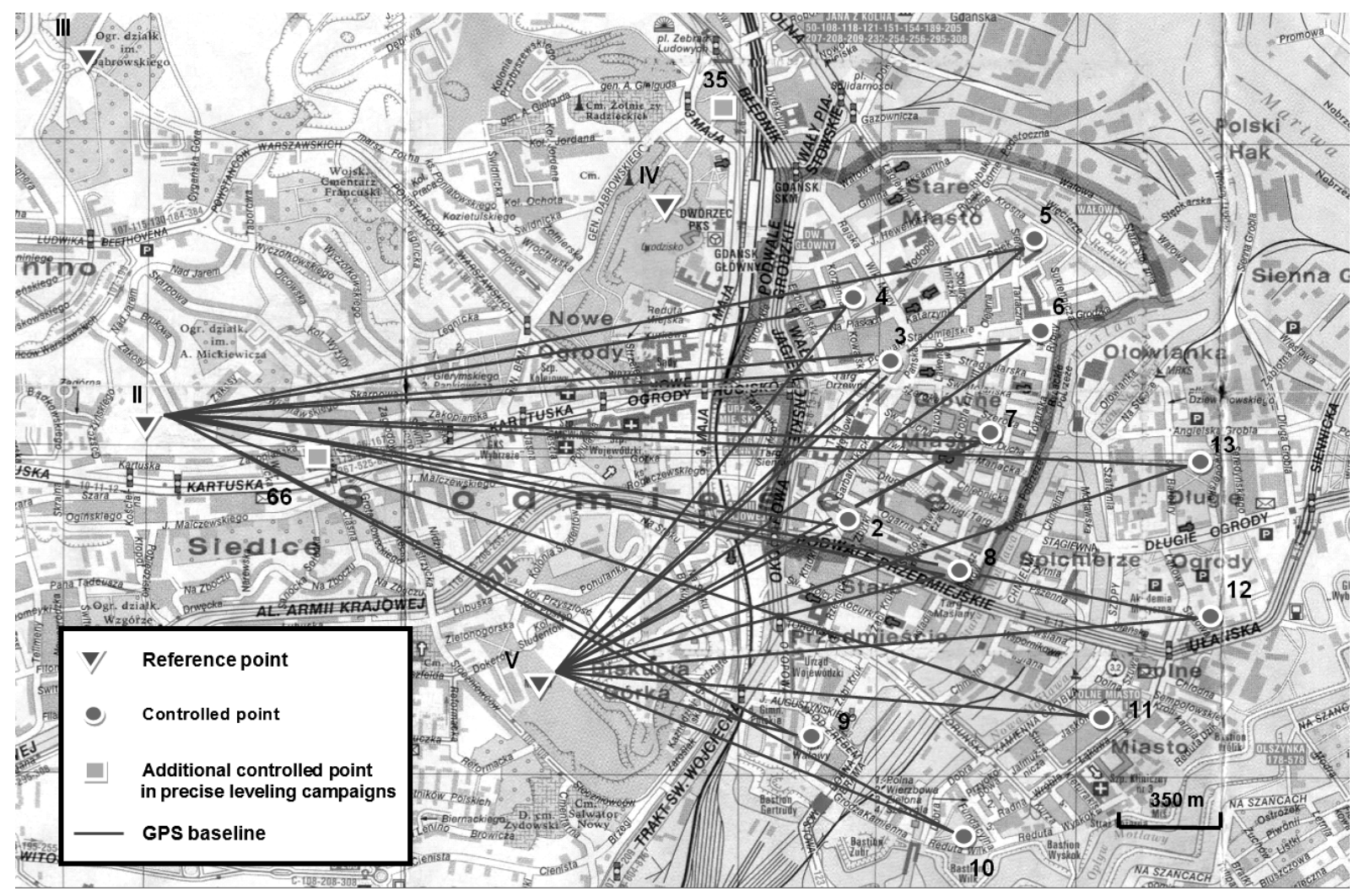

Fig. 1 The control network of ground deformation studies by apply GPS strategy described in the papers (Baryła et al., 2009; Baryła and Paziewski, 2012), located in the area of the Old and Main City of Gdansk.

The main aim of this paper is to present the basic properties of method of $\mathrm{M}_{\text {split }}$ estimation and an indication of its possible applications in deformation analysis of the geodetic networks. As a test object a leveling control network was selected, which is located in the area of the Old and Main City of Gdansk. The leveling network was measured in two measurements campaigns by using the precise geometric leveling. The results of $\mathrm{M}_{\text {split }}$ estimation were compared with the results of the classical least squares method and with the results of the optimal strategy for ground deformation monitoring by using Global Positioning System (GPS) measurement (which was developed in the Chair of Satellite Geodesy and Navigation in Olsztyn). The article ends with the conclusion which demonstrating strengths and weaknesses of the proposed computational strategy in the geodetic determining of displacements.

\section{EXPERIMENT}

The control network considered in this paper has been designed in the area of the Old and Main City of Gdansk. The construction of a test network constitutes the four reference points and twelve controlled points. The idea of the monitoring was to determine the deformation indicators of geodetic control network based on independent development of GPS vectors (Fig. 1).

The GPS measurement procedures are divided into two main stages: analysis of reference points stability and determine the coordinates of the monitored points. The reference points stability analysis showed that developed GPS strategy is optimal when the points PP02 and PP05, will form the reference datum (Fig. 1.). It should be noted, that position of the reference point PP03 was changed in time. Research showed that between the first and fifth measurement epochs, the vertical component of coordinates of the reference point PP03 had significantly changed $(-24 \mathrm{~mm})$. The optimal procedure of GPS strategy of determining the monitored points displacement by applying Bernese 5.0 software, was described in detail in the papers (Baryła et al., 2009, 2012, 2014). In the years from 2006 to 2009, the five GPS measurements campaigns were performed. Additionally, during the third and fifth GPS measurement campaigns, two measurements campaigns of the precise geometric leveling were carried out. The geometric leveling campaigns accounted for the control of the results obtained by the optimal precise GPS measurements strategy applied for leveling network monitoring (developed by the staff of the Chair of Satellite Geodesy and Navigation in Olsztyn). 


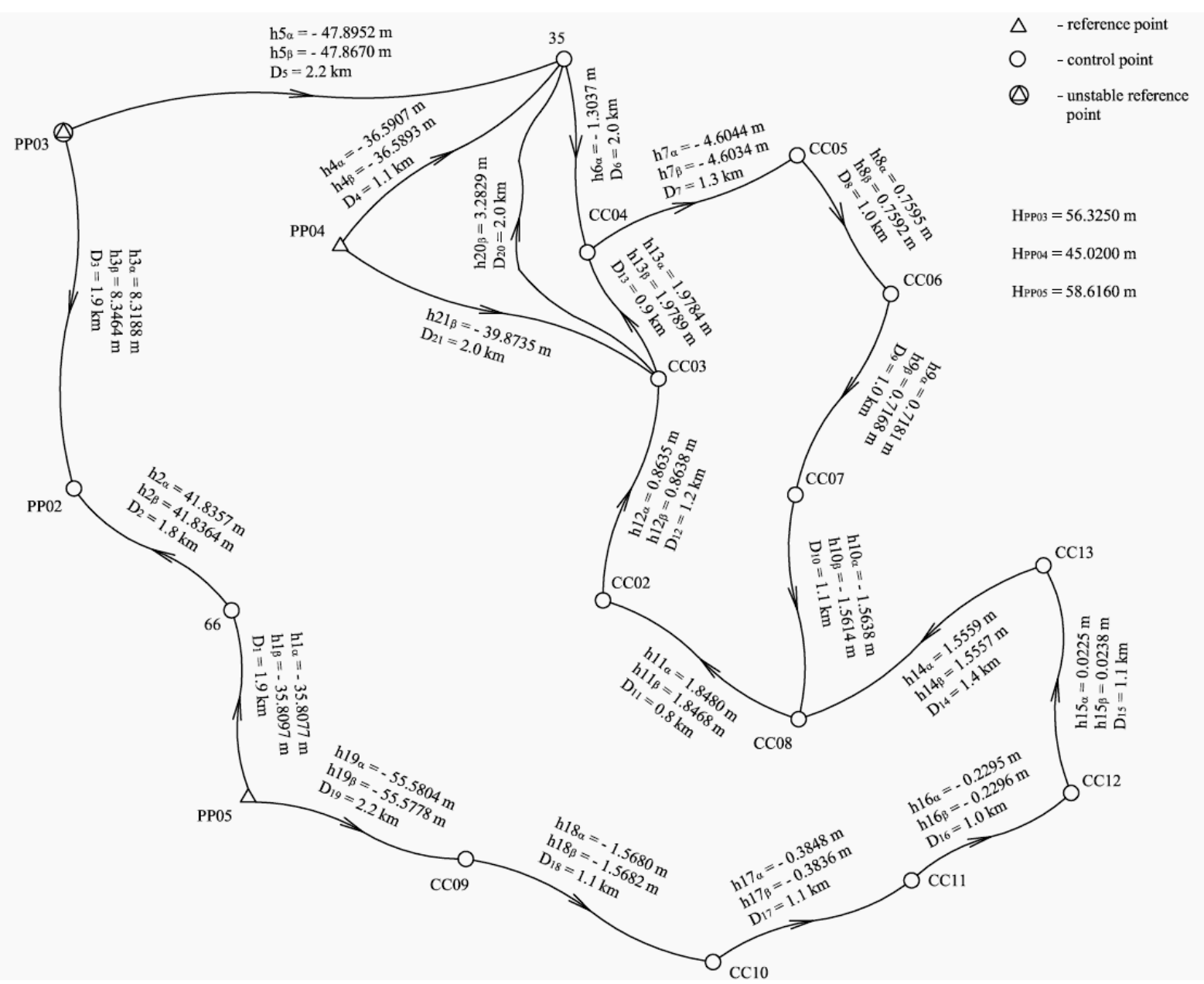

Fig. 2 The sketch of the leveling control network designed in the area of the Old and Main City of Gdansk.

The sketch of performed precise geometric leveling is presented in Figure 2. On this sketch the geometry of the control network for both measurement epochs is presented. Additionally, the sketch contains the information concerning the value of the high differences between points, the coordinates of reference points in the Kronsztadt system and the leveling lengths. In both precise leveling campaigns, the points 66 and 35 join to the monitored points. These points, in reality, are the geodetic reference points of second class. Additionally, for experiment the reference points PP03, PP04 and PP05 were adopted as a reference frame. The PP02 point was included in the set of monitored points. Thus, a reference point which will generate the outliers, will participate in a reference frame. It is well known that in this case the application of the method of the least squares (LSE), which belongs to a broad family of M - estimation methods, does not provide any reliable about an examined object. This is due to a very high sensitivity of LS estimators for the outliers (e.g. Duchnowski and Wiśniewski, 2014; Guo et. al., 2010). In this experiment authors test the application of method of $\mathrm{M}_{\text {split }}$ estimation to determine of the monitored points displacements in case, when reference datum is unstable. The results of the method of estimation parameters in a split functional model of geodetic observations were compared with the results of the least squares method (LS estimates - variant I). The LS estimators were also determined on the assumption that earlier the test of reference points stability was performed and instability of reference point PP03 was detected. In this variant point PP03 is included in the set of monitored points (LS estimates variant II). The obtained results were also compared with displacements of the monitored points obtained by GPS measurements (the results of GPS strategy were taken from the paper Baryła et al., 2009).

\section{THEORETICAL FOUNDATIONS OF $M_{S P L I T}$ ESTIMATION}

Let's assume, that the observation set $\mathbf{y}=\left[y_{1}, y_{2}, \ldots, y_{n}\right]^{T}$ is undetermined mixture of three random variables $Y_{\alpha} \sim P_{X_{\alpha}}, \quad Y_{\beta} \sim P_{X_{\beta}} \quad$ and $Y_{\zeta} \sim P_{X_{\zeta}}$. The variable $Y_{\alpha}$ and $Y_{\beta}$ concern to the first and second measurement epoch, respectively, while $Y_{\zeta}$ concern the outliers. This assumption leads to the split of conventional 
functional model of geodetic observations into three competitive versions (Wiśniewski, 2010; Zienkiewicz, 2015):

$$
\mathbf{v}=\mathbf{y}-\mathbf{A X} \stackrel{\text { split }}{\longrightarrow}\left\{\begin{aligned}
\mathbf{v}_{\alpha} & =\mathbf{y}-\mathbf{A} \mathbf{X}_{\alpha} \\
\mathbf{v}_{\beta} & =\mathbf{y}-\mathbf{A} \mathbf{X}_{\beta} \\
\mathbf{v}_{\text {virtual }} & =\mathbf{y}-\mathbf{A} \mathbf{X}_{\text {virtual }}
\end{aligned}\right.
$$

The value called an elementary split potential determines to which of the competitive functional models belongs a particular observation (Wiśniewski, 2009). Therefore, we do not need to have organized sets of particular realizations of random variables. Determination of competitive versions of the parameter $X$ in a split functional model occurs by solving the following optimization criterion (Wiśniewski, 2010; Zienkiewicz 2015):

$$
\min _{\mathbf{X}_{\alpha}, \mathbf{X}_{\beta}, \mathbf{X}_{\text {virtual }}} \phi\left(\mathbf{y}, \mathbf{X}_{\alpha}, \mathbf{X}_{\beta}, \mathbf{X}_{\text {virtual }}\right)=\phi\left(\mathbf{y}, \hat{\mathbf{X}}_{\alpha}, \hat{\mathbf{X}}_{\beta}, \hat{\mathbf{X}}_{\text {virtual }}\right)
$$

In practice, in place of the general objective function the most commonly used are squared functions (eg. in the case of adoption of the normal distribution as a probabilistic model of measurement errors). Therefore, the practical application finds a articular case of $\mathrm{M}_{\text {split(q) }}$ estimation, i.e. squared $\mathrm{M}_{\text {split(q) }}$ estimation with the following objective function (Wiśniewski 2010):

$$
\phi\left(\mathbf{y}, \mathbf{X}_{\alpha}, \mathbf{X}_{\beta}, \mathbf{X}_{\text {virtual }}\right)=\sum_{i=1}^{n} p_{i} v_{i \alpha}^{2} v_{i \beta}^{2} v_{\text {ivirtual }}^{2}
$$

By the $p_{i}=\frac{1}{m_{h_{i}}^{2}}$ was indicated the weight of observation $y_{i}$, where $m_{h_{i}}$ is a mean error of height differences between two points. In leveling network the square of mean error of height differences can be defined as $m_{h_{i}}^{2}=\frac{D_{i}}{D_{n o r m}} m_{h / k m}^{2}$ (e.g. Wiśniewski, 2014a), where $D_{i}$ - leveling strings length in kilometers $[\mathrm{km}], D_{\text {norm }}$ - normative length $(1 \mathrm{~km})$ of leveling strings, $m_{h / \mathrm{km}}$ - accuracy of measurement of the $1 \mathrm{~km}$ of leveling network in millimeters (standard deviation). In the considered experiment, it was assumed that the accuracy of measurement of the $1 \mathrm{~km}$ of leveling network is equal \pm 0.3 millimeters, because measurements were conducted by Leica DNA 03 instrument. The solution of the optimization problem (2) by applying the objective function (3) for the triple split functional model (1) leads to obtain the $\mathrm{M}_{\text {split }}$ estimators $\hat{\mathbf{X}}_{\alpha}, \hat{\mathbf{X}}_{\beta}$ and $\hat{\mathbf{X}}_{\text {virtual }}$ fulfilling a sufficient condition for a minimum of the objective function, i.e., the gradients of the objective function are zero vectors. Additionally, designating the Hessians form of the objective function (3), the following solution of the optimization problem of $\mathrm{M}_{\text {split }}$ estimation can be described by applying Newton's method (Wiśniewski, 2009, 2010):

$$
\left\{\begin{array}{c}
\mathbf{X}_{\alpha}^{j}=\mathbf{X}_{\alpha}^{j-1}+d \mathbf{X}_{\alpha}^{j}=\mathbf{X}_{\alpha}^{j-1}+\left[\mathbf{A}^{T} \mathbf{w}_{\alpha}\left(\mathbf{v}_{\beta}^{j-1}, \mathbf{v}_{\text {virtual }}^{j-1}\right) \mathbf{P}_{\mathbf{y}} \mathbf{A}\right]^{-1} \mathbf{A}^{T} \mathbf{w}_{\alpha}\left(\mathbf{v}_{\beta}^{j-1}, \mathbf{v}_{\text {virtual }}^{j-1}\right) \mathbf{P}_{\mathbf{y}} \mathbf{v}_{\alpha}^{j-1} \\
\mathbf{v}_{\alpha}^{j}=\mathbf{y}-\mathbf{A} \mathbf{X}_{\alpha}^{j} \\
\mathbf{X}_{\beta}^{j}=\mathbf{X}_{\beta}^{j-1}+d \mathbf{X}_{\beta}^{j}=\mathbf{X}_{\beta}^{j-1}+\left[\mathbf{A}^{T} \mathbf{w}_{\beta}\left(\mathbf{v}_{\alpha}^{j}, \mathbf{v}_{\text {virtual }}^{j-1}\right) \mathbf{P}_{\mathbf{y}} \mathbf{A}\right]^{-1} \mathbf{A}^{T} \mathbf{w}_{\beta}\left(\mathbf{v}_{\alpha}^{j}, \mathbf{v}_{\text {virtual }}^{j-1}\right) \mathbf{P}_{\mathbf{y}} \mathbf{v}_{\beta}^{j-1} \\
\mathbf{v}_{\beta}^{j}=\mathbf{y}-\mathbf{A} \mathbf{X}_{\beta}^{j} \\
\mathbf{X}_{\text {virtual }}^{j}=\mathbf{X}_{\text {virtual }}^{j-1}+d \mathbf{X}_{\text {virtual }}^{j}=\mathbf{X}_{\text {virtual }}^{j-1}+\left[\mathbf{A}^{T} \mathbf{w}_{\text {virtual }}\left(\mathbf{v}_{\alpha}^{j}, \mathbf{v}_{\beta}^{j}\right) \mathbf{P}_{\mathbf{y}} \mathbf{A}\right]^{-1} \mathbf{A}^{T} \mathbf{w}_{\text {virtual }}\left(\mathbf{v}_{\alpha}^{j}, \mathbf{v}_{\beta}^{j}\right) \mathbf{P}_{\mathbf{y}} \mathbf{v}_{\text {virtual }}^{j-1} \\
\mathbf{v}_{\text {virtual }}^{j}=\mathbf{y}-\mathbf{A} \mathbf{X}_{\text {virtual }}^{j}
\end{array}\right.
$$

Where $\mathbf{w}_{\alpha}\left(\mathbf{v}_{\beta}, \mathbf{v}_{\text {virtual }}\right), \mathbf{w}_{\beta}\left(\mathbf{v}_{\alpha}, \mathbf{v}_{\text {virtual }}\right), \mathbf{w}_{\text {virtual }}\left(\mathbf{v}_{\alpha}, \mathbf{v}_{\beta}\right)$ are weight matrices, which in the squared $M_{\text {split(3) }}$ estimation can be written in the following form: 
Table 1 The results of the estimation of the parameters in the leveling network.

\begin{tabular}{crrrrrr}
\hline & $\hat{\mathbf{X}}_{L S_{\alpha}}$ & $\hat{\mathbf{X}}_{L S_{\beta}}^{I}$ & $\hat{\mathbf{X}}_{L S_{\beta}}^{I I}$ & $\hat{\mathbf{X}}_{M \text { split }(3)_{\alpha}}$ & $\hat{\mathbf{X}}_{M \text { split }(3)_{\beta}}$ & $\hat{\mathbf{X}}_{\text {Msplit }(3)_{\text {virual }}}$ \\
\cline { 2 - 7 } No. points & & & \multicolumn{1}{c}{$[\mathrm{m}]$} & & \\
\hline CC02 & $\mathbf{4 . 2 8 2 4}$ & 4.2864 & $\mathbf{4 . 2 8 3 2}$ & $\mathbf{4 . 2 8 2 7}$ & $\mathbf{4 . 2 8 3 0}$ & 4.2781 \\
CC03 & $\mathbf{5 . 1 4 6 3}$ & 5.1504 & $\mathbf{5 . 1 4 6 9}$ & $\mathbf{5 . 1 4 6 5}$ & $\mathbf{5 . 1 4 6 5}$ & 5.1416 \\
CC04 & $\mathbf{7 . 1 2 4 9}$ & 7.1292 & $\mathbf{7 . 1 2 5 7}$ & $\mathbf{7 . 1 2 4 9}$ & $\mathbf{7 . 1 2 5 4}$ & 7.1543 \\
CC05 & $\mathbf{2 . 5 2 0 5}$ & 2.5255 & $\mathbf{2 . 5 2 2 2}$ & $\mathbf{2 . 5 2 1 5}$ & $\mathbf{2 . 5 2 1 6}$ & 2.5499 \\
CC06 & $\mathbf{3 . 2 7 9 9}$ & 3.2845 & $\mathbf{3 . 2 8 1 3}$ & $\mathbf{3 . 2 8 1 0}$ & $\mathbf{3 . 2 8 0 8}$ & 3.2770 \\
CC07 & $\mathbf{3 . 9 9 8 0}$ & 4.0011 & $\mathbf{3 . 9 9 8 0}$ & $\mathbf{3 . 9 9 7 8}$ & $\mathbf{3 . 9 9 7 6}$ & 3.9951 \\
CC08 & $\mathbf{2 . 4 3 4 2}$ & 2.4395 & $\mathbf{2 . 4 3 6 5}$ & $\mathbf{2 . 4 3 4 7}$ & $\mathbf{2 . 4 3 6 2}$ & 2.4313 \\
CC09 & $\mathbf{3 . 0 3 6 3}$ & 3.0391 & $\mathbf{3 . 0 3 8 2}$ & $\mathbf{3 . 0 3 8 2}$ & $\mathbf{3 . 0 3 7 3}$ & 3.0356 \\
CC10 & $\mathbf{1 . 4 6 8 6}$ & 1.4713 & $\mathbf{1 . 4 7 0 0}$ & $\mathbf{1 . 4 7 0 1}$ & $\mathbf{1 . 4 6 9 3}$ & 1.4674 \\
CC11 & $\mathbf{1 . 0 8 4 2}$ & 1.0881 & $\mathbf{1 . 0 8 6 5}$ & $\mathbf{1 . 0 8 4 6}$ & $\mathbf{1 . 0 8 5 7}$ & 1.0826 \\
CC12 & $\mathbf{0 . 8 5 5 0}$ & 0.8589 & $\mathbf{0 . 8 5 6 9}$ & $\mathbf{0 . 8 5 5 1}$ & $\mathbf{0 . 8 5 6 2}$ & 0.8530 \\
CC13 & $\mathbf{0 . 8 7 7 8}$ & 0.8831 & $\mathbf{0 . 8 8 0 7}$ & $\mathbf{0 . 8 7 8 9}$ & $\mathbf{0 . 8 8 0 3}$ & 0.8755 \\
35 & $\mathbf{8 . 4 2 9 2}$ & 8.4381 & $\mathbf{8 . 4 3 0 3}$ & $\mathbf{8 . 4 2 9 4}$ & $\mathbf{8 . 4 3 0 6}$ & 8.4580 \\
66 & $\mathbf{2 2 . 8 0 8 2}$ & 22.8160 & $\mathbf{2 2 . 8 0 6 5}$ & $\mathbf{2 2 . 8 0 7 5}$ & $\mathbf{2 2 . 8 0 6 8}$ & 22.8110 \\
PP02 & $\mathbf{6 4 . 6 4 3 9}$ & 64.6617 & $\mathbf{6 4 . 6 4 3 2}$ & $\mathbf{6 4 . 6 4 3 8}$ & $\mathbf{6 4 . 6 4 3 3}$ & 64.6714 \\
PP03 & - & - & $\mathbf{5 6 . 2 9 7 0}$ & - & - & - \\
\hline
\end{tabular}

$\mathbf{w}_{\alpha}\left(\mathbf{v}_{\beta}, \mathbf{v}_{\text {virtual }}\right)=\operatorname{Diag}\left(\mathbf{v}_{\beta} * \mathbf{v}_{\beta}\right) \operatorname{Diag}\left(\mathbf{v}_{\text {virtual }} * \mathbf{v}_{\text {virtual }}\right)$

$\mathbf{w}_{\beta}\left(\mathbf{v}_{\alpha}, \mathbf{v}_{\text {virtual }}\right)=\operatorname{Diag}\left(\mathbf{v}_{\alpha} * \mathbf{v}_{\alpha}\right) \operatorname{Diag}\left(\mathbf{v}_{\text {virtual }} * \mathbf{v}_{\text {virtual }}\right)$

$\mathbf{w}_{\text {virtual }}\left(\mathbf{v}_{\alpha}, \mathbf{v}_{\beta}\right)=\operatorname{Diag}\left(\mathbf{v}_{\alpha} * \mathbf{v}_{\alpha}\right) \operatorname{Diag}\left(\mathbf{v}_{\beta} * \mathbf{v}_{\beta}\right)$

where $*$ is the Hadamard product (e.g. Rao, 1973). In this case, the outliers (e.g. generated by the unstable reference points) are assigned to the estimator $\hat{\mathbf{X}}_{\text {virtual }}$. Thus, the obtained values of the parameters $\hat{\mathbf{X}}_{\alpha}$ and $\hat{\mathbf{X}}_{\beta}$, are free from the influence of the outliers. The iterative process can be started by using the least squares estimators. Assuming that the estimated parameters are vectors concerning the coordinates of the monitored points in two measurement epochs, the value of the shift between these control points can be determined from the following formula:

$\Delta_{\mathbf{X}}=\mathbf{X}_{\beta}-\mathbf{X}_{\alpha}$

It should be noted, that in the geodetic deformation analysis the information about the value of the coordinates of monitored points is not the most important task, but only the dynamics of their change. For that reason, in the geodesic determining of displacements are often used the methods which the natural properties is to determine the direct shift between the parameters, for example, the methods belonging to the R - estimation class (e.g. Duchnowski, 2013). The example of such method is also a particular version of the method of estimation parameters in a split functional model of geodetic observation, called Shift $\mathrm{M}_{\text {split }}$ estimation (Duchnowski and Wiśniewski, 2012).

\section{RESULTS}

Estimation parameters by the least squares method $\left(\hat{\mathbf{X}}_{L S_{\beta}}^{I}\right)$ clearly demonstrated the negative influence of an unstable reference point on the designated values of the coordinates of the monitored points (Table 1). etermined on their basis the shifts between monitored points can lead to misinterpretation of the state of the tested object (Table 2). In Table 1 the vectors of estimated coordinates displayed in bold can be considered as good.

The indicator of deformation obtained for point PP02 clearly show the displacement of a point $\hat{\Delta}_{L S-P P 02}^{I}=17.8 \mathrm{~mm}$. The deformation indicators obtained for the monitored points $35\left(\hat{\Delta}_{L S-35}^{I}=8.9 \mathrm{~mm}\right)$ and 66 $\left(\hat{\Delta}_{L S-66}^{I}=7.8 \mathrm{~mm}\right.$ ) could also indicate for a potential displacements of these points. The exclusion of point PP03 from reference frame and inclusion it to the group of monitored points radically changed the value of obtained vertical deformation indicators. The maximum difference in coordinates of the monitored points is 
Table 2 The values of monitored points displacements.

\begin{tabular}{ccccc}
\hline \multirow{2}{*}{ No. points } & $\hat{\boldsymbol{\Delta}}_{L S}^{I}$ & $\hat{\boldsymbol{\Delta}}_{L S}^{I I}$ & $\hat{\boldsymbol{\Delta}}_{G P S}$ & $\hat{\boldsymbol{\Delta}}_{M_{\text {split }} \text { estimation }}$ \\
\cline { 2 - 4 } & & \multicolumn{2}{c}{$[\mathrm{m}]$} & 0.0036 \\
CC02 & 0.0040 & 0.0008 & -0.0010 & 0.0003 \\
CC03 & 0.0041 & 0.0006 & 0.0002 & 0.0000 \\
CC04 & 0.0043 & 0.0008 & -0.0026 & 0.0001 \\
CC05 & 0.0050 & 0.0017 & -0.0030 & -0.0002 \\
CC06 & 0.0046 & 0.0014 & -0.0058 & -0.0002 \\
CC07 & 0.0031 & 0.0000 & 0.0045 & 0.0015 \\
CC08 & 0.0053 & 0.0023 & 0.0031 & -0.0009 \\
CC09 & 0.0028 & 0.0019 & 0.0017 & -0.0008 \\
CC10 & 0.0027 & 0.0014 & 0.0037 & 0.0011 \\
CC11 & 0.0039 & 0.0023 & 0.0046 & 0.0011 \\
CC12 & 0.0039 & 0.0019 & -0.0004 & 0.0014 \\
CC13 & 0.0053 & 0.0029 & - & 0.0012 \\
35 & 0.0089 & 0.0011 & - & -0.0007 \\
66 & 0.0078 & -0.0017 & - & -0.0005 \\
\hline
\end{tabular}

$\hat{\Delta}_{L S-C C 13}^{I I}=2.9 \mathrm{~mm}$ for point CC13. The obtained results can be interpreted as a confirmation of stability of the monitored points spread over the area of the Old and Main City of Gdansk. Of course, the study was performed in the small area, where the monitoring points were relative close to the reference points. Therefore, it is not excluded that the monitored object and the area in which the reference points were located, were displaced by the same vector. The results of the GPS strategy (Baryła et. al., 2009) confirm the results of the second variant of LS estimators obtained using the adjustment of the classical leveling network. The determined displacements based on the GPS observations are characterized by lower accuracy than deformation indicators obtained on the basis of the precise geometric leveling (e.g. displacements of the points $\mathrm{CC} 07, \mathrm{CC} 08$ and CC12). However, this may be due to e.g. various structure of control network or choice of different reference points.

It should be noted, that the use of $\mathrm{M}_{\text {split }}$ stimation significantly reduce the influence of an unstable reference point on designated displacements. The triple split of functional model caused, that the outliers generated by unstable reference point, have been assigned to the virtual functional model. Thus, the value of the estimators $\hat{\mathbf{X}}_{M \operatorname{split}(3)_{\alpha}}$ and $\hat{\mathbf{X}}_{M \operatorname{split}(3)_{\beta}}$ were freed from the influence of the outliers. The displacements values obtained based on the $\mathbf{M}_{\text {split }}$ estimators $\hat{\mathbf{X}}_{M \operatorname{split}(3)_{\alpha}}$ and $\hat{\mathbf{X}}_{M_{\operatorname{split}(3)_{\beta}}}$ are a very similar to the LS estimators in variant II, in which assumed that the instability of the reference point was detected. The maximum difference between the monitored points coordinates observed for the points are: $\quad \hat{\Delta}_{C C 08}^{M_{\text {split }}}=1.5 \mathrm{~mm}$ and $\hat{\Delta}_{C C 13}^{M_{\text {split }}}=1.4 \mathrm{~mm}$. The graphical interpretation of the obtained displacements of the monitored points is illustrated in Figure 3. The absence of deformation indicators for the points 35 and 66 for GPS strategy is due to the inability to measure these points using satellite positioning techniques.

\section{CONCLUSION}

The topics discussed in this paper concern the appointment of the vertical indicators of deformations, in the case where the reference datum is unstable. In practice, the determination of the monitored points displacements is usually preceded by the study of the reference points stability. There are also methods of limiting the influence of the outlying observations and outlying points on the determined displacement between the monitored points used, for example, the robust $M$ - estimation. The limitation of influence of the outliers on the final form of the estimators can be also achieve by applying the method of the estimation parameters in a split functional model (e.g. Ge et al., 2013; Wiśniewski, 2009; Zienkiewicz, 2015). A characteristic feature of the presented method is that the competitive versions of the parameter $\mathbf{X}$ are determined on the basis of a one vector of observations $\mathbf{y}$. An important property of the $\mathrm{M}_{\text {split }}$ estimation is that the observations during the estimation are "spontaneously" assigned to the corresponding functional model. This property may be particularly important in the situation where the observation set is an undetected set of the realization of a several random variables. However, this method can be also used in the case when the assignment of observations to a particular random variable is well known, e.g., the measurement of the geodetic network in two measurement epochs. 


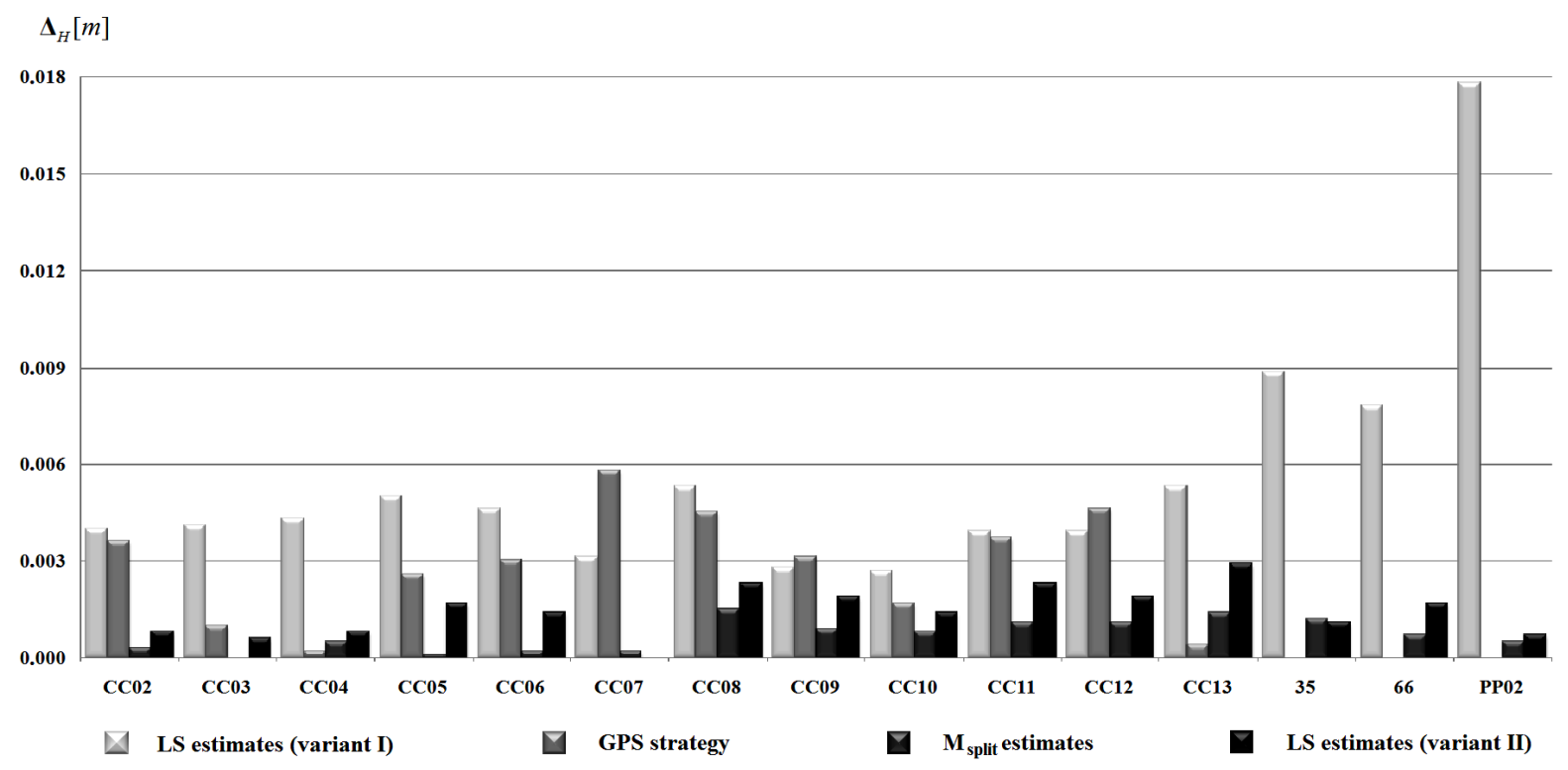

Fig. 3 The absolute values of obtained displacements of the monitored points.

As a tested object the control network in the area of the Old and Main City of Gdansk was chosen, which were measured in two measurement campaigns of precise geometric leveling. The numerical example presented in this paper shows that the method based on the split of the conventional functional model can be an alternative for traditional methods of determining the displacements. $\mathrm{M}_{\text {split }}$ estimators $\left(\hat{\mathbf{X}}_{M \text { split(3) })_{\alpha}}\right.$ and $\hat{\mathbf{X}}_{M_{\text {split(3) }}{ }_{\beta}}$ ) computed for unstable reference datum, have a similar values as the least squares estimators $\left(\hat{\mathbf{X}}_{L S_{\alpha}}\right.$ and $\hat{\mathbf{X}}_{L S_{\beta}}^{I I}$ ) determined in the variant, in which assumed that the instability of reference point PP03 was detected. Thus, it can be said that the shifts of the monitored points determined on the basis of $\mathrm{M}_{\text {split }}$ estimators provide the reliable information about monitored object. Additionally, the displacements determined on the basis of precise geometric leveling are similar to a shifts obtained by precise GPS leveling. The maximal values of the vertical indicators are respectively $1.5 \mathrm{~mm}$ for the $\mathrm{M}_{\text {split }}$ estimation, $2.9 \mathrm{~mm}$ for the least squares method (variant II), and $-5.8 \mathrm{~mm}$ for the precise GPS leveling. The obtained results confirm the usefulness of the $\mathrm{M}_{\text {split }}$ estimation in the methodology of geodetic determining of the displacements. It should be noted, that two measurement campaigns of precise geometric leveling, which were carried out in the area of the Old and Main City of Gdansk, were only a control of results obtained by GPS leveling. Therefore, the structure of geometric leveling network was reduced to a minimal mutual control between the observations. For that reason, the degree of control network reliability for potential outliers is not to high. It can lead to a inefficiency of the proposed computational algorithm in the case of several unstable reference points or appearance of a gross errors in observations (similar like in the case of robust $\mathrm{M}$ - estimation). In the case of geodetic network with a high internal reliability the method of $\mathrm{M}_{\text {split }}$ estimation should be characterized by a high efficacy in process of determining the displacements of the monitored points.

\section{REFERENCES}

Baarda, W.: 1968, A testing procedure for use in geodetic network. Neth Geod Comm Publ Geod. New Ser, 2, No. 5.

Banaś, M. and Ligas, M.: 2014, Empirical tests of performance of some M - estimators. Geodesy and Cartography, 63, No. 2, 127-146.

DOI: $10.2478 /$ geocart-2014-0010

Baryła, R., Oszczak, S., Wielgosz, P. and Koczot, B.: 2009, The concept of using GPS technology to deformation of the Earth's surface study in urban areas. Prace Naukowe Instytutu Górnictwa Politechniki Wrocławskiej, 129, 9-17, (in Polish).

Baryła, R. and Paziewski, J.: 2012, Principles of the ground deformation monitoring technology based on GPS satellite measurements in control network. Biuletyn Wojskowej Akademii Technicznej, 61, No. 2, 39-57, (in Polish).

Baryła, R., Paziewski, J., Wielgosz, P., Stępniak, K. and Krukowska, M.: 2014, Accuracy assessment of the ground deformation monitoring with the use of GPS local network: open pit mine Kozmin case study. Acta Geodyn. Geomater., 11, No. 4 (176), 317-324.

DOI: $10.13168 /$ AGG.2014.0013

Caspary, W.F.: 1988, Concepts of network and deformation analysis. The University of New South Wales, Kensington.

Cellmer, S.: 2014, Least fourth powers: optimisation method favouring outliers. Survey Review. DOI: $10.1179 / 1752270614$ Y.0000000142 
Czaplewski, K. and Wiśniewski, Z.: 2008, Hybrid M estimation in Maritime Navigation. Polish Journal of Environmental Studies, 17, No. 5A, 25-31.

Duchnowski, R.: 2010, Median-based estimates and their application in controlling reference mark stability. J. Surv. Eng., 136, No.2, 47-52. DOI: 10.1061(ASCE)SU.1943-5428.0000014

Duchnowski, R.: 2011, Robustness of strategy for testing leveling mark stability based on rank tests. Survey Review, 43, No. 323, 687-699. DOI: $10.1179 / 003962611 X 13117748892551$

Duchnowski, R.: 2013, Hodges - Lehmann estimates in deformation analyses. Journal of Geodesy, 87, No. 1012, 873-884. DOI: 10.1007/s00190-013-0651-2

Duchnowski, R. and Wiśniewski, Z.: 2012, Estimation of the shift between parameters o functional models of geodetic observations by applying $\mathrm{M}_{\text {split }}$ estimation. $\mathrm{J}$. Surv. Eng., 138, No.1, 1-8. DOI: 10.1061/(ASCE)SU.1943-5428.0000062

Duchnowski, R. and Wiśniewski, Z.: 2014, Comparison of two unconventional methods of estimation applied to determine network point displacement. Survey Review, 46, No. 339, 401-405. DOI: $10.1179 / 1752270614$ Y.0000000127

Erol, S., Erol, B. and Ayan, T.: 2004, General overview of the deformation monitoring techniques and A case study: Analysing deformations using GPS/Levelling, In: Proc. ISPRS 2004 XXI General Assembly, 12-23 July Istanbul, Turkey.

Ge, Y., Yuan, Y. and Jia, N.: 2013, More efficient methods among commonly used robust estimation methods for GPS coordinate transformation. Survey Review, 45, No. 330, 229-234. DOI: $10.1179 / 1752270612$ Y.0000000028

Guo, J., Ou, J. and Wang, H.: 2010, Robust estimation for correlated observation: two local sensitivity - based downweighting strategies. Journal of Geodesy, 84, No. 4, 243-250. DOI: 10.1007/s00190-009-0361-y

Hekimoglu, S., Erdogan, B., Erenoglu, R.C. and Hosbas, R.G.: 2011, Increasing the efficacy of the tests for outliers for geodetic networks. Acta Geodaetica et Geophysica Hungarica, 46, No.3, 291-308.

DOI: 10.1556/AGeod.46.2011.3.2

Hekimoglu, S. and Koch, K.R.: 1999, How can reliability of robust methods be measured? Third Turkish-German Joint Geodetic Days, Istanbul 1, 179-196.

Hekimoglu, S. and Koch, K.R.: 2000, How can reliability of the test for outliers be measured? Allgemeine Vermessungs-Nachrichten, 107, No. 7, 247-253.

Huber, P.J.: 1981, Robust Statistics. Wiley, New York, 308 pp.

Kashani, I., Wielgosz, P. and Grejner-Brzezinska, D.A.: 2007, The impact of the ionospheric correction latency on long-baseline instantaneous kinematic GPS positioning. Survey Review, 39. No. 305, 238-251. DOI: $10.1179 / 175227007 \mathrm{X} 197156$

Labant, S., Weiss, G. and Kukučka, P.: 2011, Adjustment of a geodetic network measured by a satellite technology in the Dargovskych Hrdinov Suburb. Acta Montanistica Slovaca, 16, No. 3, 229-237.

Langbein, J.O.: 2003, Deformation of the Long Valley Caldera. California: inferences from measurement from 1988 to 2001. Journal of Volcanology and Geothermal Research, 127, 247-267. DOI: $10.1016 / \mathrm{S} 0377-0273(03) 00172-0$

Nowel, K. and Kamiński, W.: 2014, Robust estimation of deformation from observation differences for free control networks. Journal of Geodesy, 88, No. 8, 749764. DOI: $10.1007 / \mathrm{s} 00190-014-0719-7$

Nowel, K.: 2015a, Investigating the efficacy of robust M estimation of deformation from observation differences. Survey Review. DOI: 10.1179/1752270614Y. 0000000150

Nowel, K.: 2015b, Robust M-Estimation in analysis of control network deformations: Classical and new method. Journal of Surveying Engineering. DOI: 10.1061/(ASCE)SU.1943-5428.0000144

Palano, M., Puglisi, G. and Gresta, S.: 2008, Ground deformation patterns at Mt. Etna from 1993 to 2000 from joint use of InSAR and GPS techniques. Journal of Volcanology and Geothermal Research, 169, No. 34, 99-120. DOI: 10.1016/j.jvolgeores.2007.08.014

Prószyński, W.: 2010, Another approach to reliability measures for systems with correlated observations. Journal of Geodesy, 84, No. 9, 547-556. DOI: $10.1007 / \mathrm{s} 00190-010-0394-2$

Rao, C.R.: 1973, Linear statistical inference and its applications. John Wiley \& Sons. Inc.

Stępniak, K., Baryła, R., Wielgosz, P. and Kurpiński, G.: 2013, Optimal data processing strategy in precise GPS leveling networks. Acta Geodyn. Geomater., 10, No. 4(172), 443-452. DOI: 10.13168/AGG.2013.0044

Štroner, M., Urban, R., Rys, P. and Balek, J.: 2014, Prague castle area local stability determination assessment by the robust transformation method. Acta Geodyn. Geomater., 11, No. 4(176), 325-336. DOI: 10.13168/AGG.2014.0020

Wielgosz, P., Paziewski, J., and Baryła R.: 2011, On constraining zenith tropospheric delays in processing of local GPS networks with bernese software. Survey Review, 43, No. 333, 472-483. DOI: $10.1179 / 003962611 X 13117748891877$

Wiśniewski, Z.: 2005, Adjustment Calculus in Geodesy. UWM Publishing Press, Olsztyn, 474 pp, (in Polish).

Wiśniewski, Z.: 2009, Estimation of parameters in a split functional model of geodetic observations $\left(\mathrm{M}_{\text {split }}\right.$ estimation). Journal of Geodesy, 83, No. 2, 105-120. DOI: $10.1007 / \mathrm{s} 00190-008-0241-\mathrm{x}$

Wiśniewski, Z:: 2010, $\mathrm{M}_{\text {split(q) }}$ estimation: estimation of parameters in a multi split functional model of geodetic observations. Journal of Geodesy, 84, No. 6, 355-372. DOI: $10.1007 / \mathrm{s} 00190-010-0373-7$

Wiśniewski, Z.: 2014a, Advanced methods of geodetic adjustment, with examples. UWM Publishing Press, Olsztyn, 496 pp, (in Polish).

Wiśniewski, Z.: 2014b, M - estimation with probabilistic models of geodetic observations. Journal of Geodesy, 88 , No. 10, 941-957. DOI: $10.1007 / \mathrm{s} 00190-014-0735-7$

$\mathrm{Xu}$, P.: 1989, On robust estimation with correlated observations. Bull. Geod., 63, No. 3, 237-252.

Yang, Y.X.: 1994, Robust estimation for dependent observation. Manuscr. Geod., 19, No.1, 10-17.

Zienkiewicz, M.H. and Bałuta, T.: 2013, Example of robust free adjustment of horizontal network covering detection of outlying points. Technical Sciences, 16, No.3, 179-192.

Zienkiewicz, M.H.: 2015, Application of $\mathrm{M}_{\text {split }}$ estimation to determine control points displacements in networks with unstable reference system. Survey Review, 47, No. 342, 174-180. DOI: $10.1179 / 1752270614$ Y.0000000105 